\title{
CrystEngComm
}

HIGHLIGHT

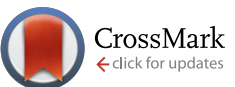

Cite this: CrystEngComm, 2015, 17, 7978

Received 29th May 2015,

Accepted 8th July 2015

DOI: $10.1039 / c 5 c e 01032 b$

www.rsc.org/crystengcomm
View Article Online

View Journal | View Issue

\section{Transformation of rigid metal-organic frameworks into flexible gel networks and vice versa}

\author{
José Juan Marrero-Tellado ${ }^{a}$ and David Díaz Díaz ${ }^{\star b c}$
}

\begin{abstract}
Understanding and controlling phase transformations is a timely subject of investigation because they are essential for the fabrication of high-performance materials with applications in energy, sensors, biomedical, and information-related technologies. Such transformations at the nanoscale arise from both diffusion kinetics and surface thermodynamics, whose reasoning represents a major intellectual challenge in multicomponent systems. In particular, the study of interconversion routes between stable and metastable states provides a useful foundation for the rational design of hard and soft materials. Here, we highlight some recent studies that have demonstrated the possibility of transforming rigid (hard) MOFs into flexible (soft) gel materials in quantitative (or nearly quantitative) yields, and vice versa albeit involving different mechanisms and starting materials. These works represent a new paradigm in the growing areas of crystal engineering and stimuli-responsive gels by building new bridges between advanced functional materials that have been traditionally studied in very different research fields.
\end{abstract}

\section{Introduction}

Viscoelastic gels ${ }^{1}$ exhibit solid-like rheological behavior under deformation $^{2}$ and have been considered promising materials for bottom-up nanofabrication in numerous research fields. ${ }^{3}$ In contrast to chemical gels, ${ }^{4}$ which are based on covalent bonds (usually cross-linked polymers), physical (or supramolecular) gels ${ }^{5}$ are made of low-molecular-weight compounds or polymers so-called gelators- that self-assemble into $1 \mathrm{D}$ fibers by non-covalent interactions (e.g., hydrogen-bonding, $\pi-\pi$ stacking, metal coordination, etc.). Subsequent entanglement of these fibers yields 3D matrices in whose interstices liquid molecules (major component) are entrapped via surface tension and capillary forces. ${ }^{6}$

On the other hand, metal-organic frameworks (MOFs) are rigid and crystalline hybrid materials consisting of organic linkers with bridging organic ligands and metal ions. Owing to their tunable surface area and pore size, they have been of great interest as functional nanoporous materials for important applications such as gas storage, separation, sensors, catalysis, and drug delivery. ${ }^{7}$ Among other methods, ${ }^{8}$ MOFs are commonly synthesized by solvothermal reactions yielding

\footnotetext{
${ }^{a}$ Departamento de Química Orgánica, IUBO, "Antonio González", Universidad de La Laguna, Astrofísico Francisco Sánchez 2, 38206 La Laguna, Tenerife, Spain ${ }^{b}$ Institut für Organische Chemie, Universität Regensburg, Universitätsstr. 31, 93040 Regensburg, Germany. E-mail: David.Diaz@chemie.uni-regensburg.de; Tel: + 499419434373

${ }^{c}$ IQAC-CSIC, Jordi Girona 18-26, 08034 Barcelona, Spain
}

uniform crystals with sharp edges and sizes ranging from nanometers to millimeters. ${ }^{9}$

In an attempt to connect both fields, the well-recognized balance between gelation and crystallization, ${ }^{10}$ has motivated numerous studies regarding the parameters that influence gel phase crystallization. ${ }^{11}$ Among these factors, solvent's nature plays a key role either during the crystallization of single gelator molecules, ${ }^{12}$ including coordination compounds as shown by Lloyd and co-workers, ${ }^{13}$ or during the assembly of various components (e.g., metal ions and organic ligands) in crystalline or amorphous phases. ${ }^{14}$ Indeed, among existing technologies to control crystal size and growth, the traditional sol-gel process has become a very important tool in which an inert gel matrix retains the crystal nuclei in its position of formation and growth. ${ }^{15}$ Yaghi and co-workers ${ }^{16}$ pioneered the use of sol-gel technique for growing MOF crystals. More recently, Steed and co-workers ${ }^{17}$ made also an important contribution to the field by employing lowmolecular-weight organogels as inert gel niches to synthesize single crystals of a range of important organic molecules with controlled polymorphism, including active pharmaceutical ingredients (APIs). Afterward, other groups ${ }^{18}$ have also validated this approach.

Despite numerous advances in the preparation and formulation of these materials, prediction of either MOF structures or the gelation ability from molecular building blocks remains a great challenge. However, a number of reports have already revealed a powerful link between 3D crystal packing of small molecules and their ability to form gel networks. ${ }^{19}$ 
None of the above relationships are obvious if we consider that occurrence of crystals is predicted by equilibrium thermodynamics whereas gelation is a kinetics process. ${ }^{20}$ Herein, we highlight some recent and pioneering contributions that have demonstrated the feasibility of transforming directly (a) rigid MOFs into flexible gel particles or (b) supramolecular metallogels into MOFs. Nevertheless, the mechanisms involved in both transformations are different because the former involves covalent cross-linking of the starting material, whereas the latter involves an exchange process of the components by intermolecular interactions.

\section{Transformation of metal-organic frameworks into polymer gels}

In 2012, Sada and co-workers ${ }^{21}$ reported the first bottom-up approach for the fabrication of nano- and microsized cubic gel particles (CGPs) with well-defined edges and square faces using MOFs with cubic shape as templates. The strategy relies on the large reaction space of the $3 \mathrm{D}$ channels in the MOFs and consisted in three steps: 1) preparation of a hydroxyl-functionalized MOF, 2) subsequent cross-linking with a suitable bifunctional electrophile, and 3) removal of coordinated metal ions. Specifically, the authors used a $\gamma$-cyclodextrin $(\gamma$-CD) MOF (CD-MOF) that was easily prepared by reacting $\gamma$-CD with $\mathrm{KOH}$ in aqueous solution, followed by standard vapor diffusion of $\mathrm{MeOH}$ into the solution (Fig. 1). This method allowed the preparation of cubic crystals with 40-500 $\mathrm{mm}$ on a side, which were easily separated by decantation or filtration. Moreover, much smaller CD-MOF crystals could be obtained from the supernatant by adding a surfactant-containing mother liquor (i.e., cetyltrimethylammonium bromide, $\mathrm{CTAB}$ ) and controlling the incubation time. Thus, uniform cubic crystals with sizes of $c a .10 \mathrm{~mm}$ (CDMOF-Micro1), $1 \mathrm{~mm}$ (CD-MOF-Micro2) and 200-300 nm (CDMOF-Nano) were obtained (Fig. 2a, c and d).

Subsequently, the cross-linking reaction of the $\gamma$-CDs in the CD-MOF pores was carried out by treatment with ethylene glycol diglycidyl ether (L) in EtOH at $65^{\circ} \mathrm{C}$ for 3 days. Finally, removal of potassium ions and unreacted $\mathrm{L}$ was achieved by soaking the obtained cross-linked CD-MOF (CL-CD-MOF) in a mixed solvent $\left(\mathrm{EtOH} / \mathrm{H}_{2} \mathrm{O}=1: 1(\mathrm{v} / \mathrm{v})\right)$ and $\mathrm{H}_{2} \mathrm{O}$, yielding

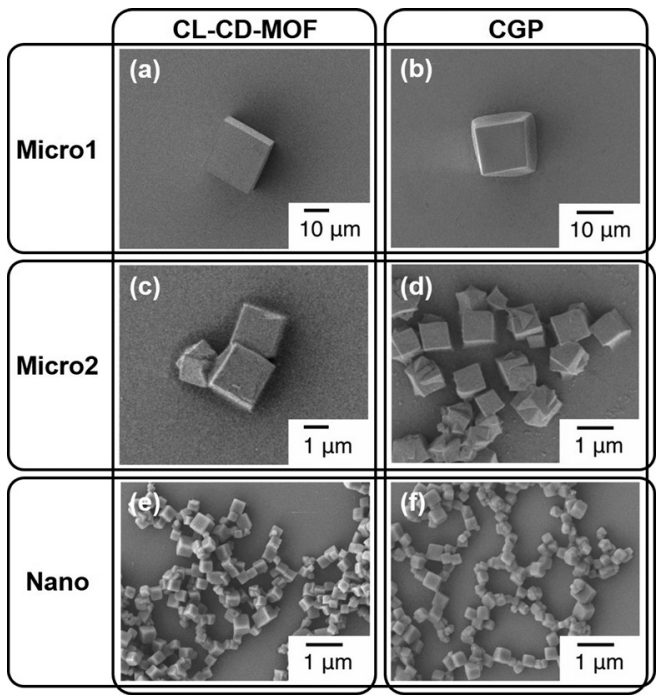

Fig. 2 SEM images of a) CL-CD-MOF-Micro1, b) CGP-Micro1, c) CLCD-MOF-Micro2, d) CGP-Micro2, e) CL-CD-MOF-Nano, and f) CGP-Nano. Adapted with permission from ref. 21. Copyright ${ }^{\circledR}$ Wiley$\mathrm{VCH}$.

CGPs with shape-memory of the starting crystalline materials (Fig. 2b, d and f).

In sharp contrast to unmodified CD-MOFs, so prepared CL-CD-MOFs swelled in $\mathrm{H}_{2} \mathrm{O}$. Although the original cubic shape of the CD-MOF was retained even after the crosslinking and degradation process, sizes of the cubes were expanded by 1.37 times the original CL-CD-MOF length (degree of swelling, ${ }^{22} Q=2.57$ ) (Fig. 3). FT-IR, elemental analysis, PXRD, and TG analyses of the so prepared CGPs confirmed that the epoxy groups of $\mathrm{L}$ reacted with the hydroxy groups of each $\gamma$-CD, rising the thermal stability of the crystalline material and inducing the network formation. For CGP, no apparent diffraction peaks were observed after removing the solvent, indicating that CL-CD-MOF became amorphous after swelling, like a polymer gel.

This work demonstrated that cubic gel particles retained the shape and size of the original CD-MOF crystals. Therefore, it is expected that a fine control on the recrystallization conditions could be used to fabricate a wide range of sizes of polyhedral gel particles (micro- and nanosized) from a variety
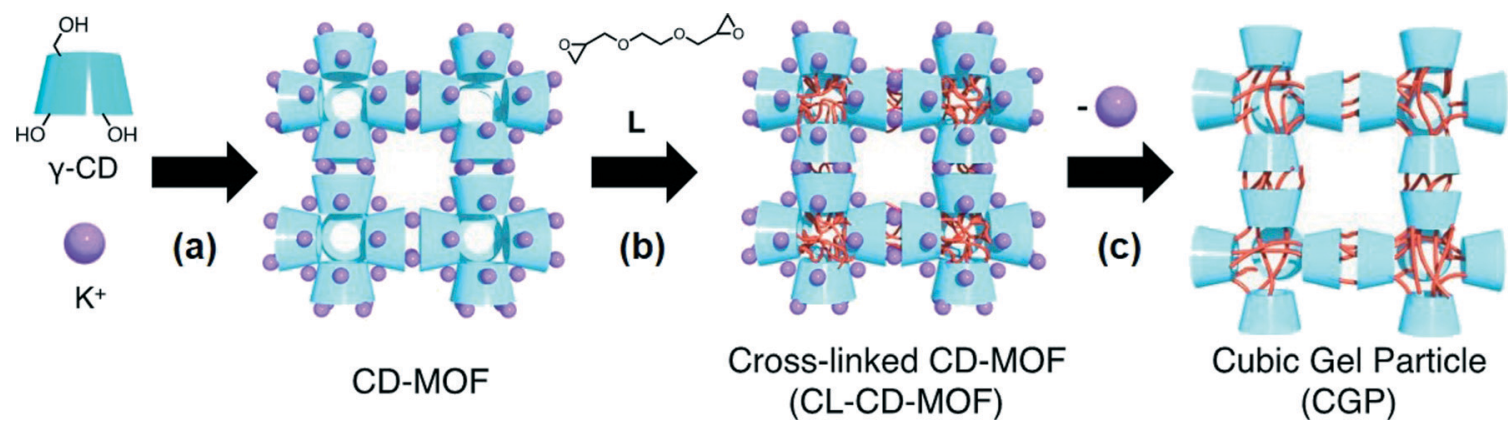

Fig. 1 Schematic illustration of the synthesis of cubic gel particles (CGP) from MOF precursor (CL-CD-MOF): a) crystallization, b) cross-linking reaction, and c) removal of coordinated metal ions. Reprinted with permission from ref. 21. Copyright@ Wiley-VCH. 


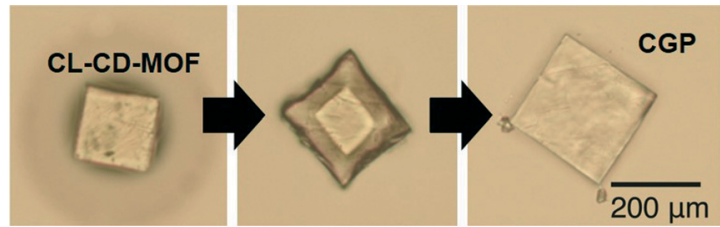

Fig. 3 MOF-to-GP transition captured by SEM. Adapted with permission from ref. 21. Copyright ${ }^{\circledR}$ Wiley-VCH.

of MOF crystals as supramolecular templates. Therefore, the use of different cross-linkers and metals ions could be used to obtain gel particles with different shapes.

In order to expand the applicability of this strategy to

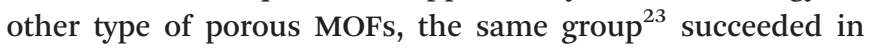
transforming the rigid coordination networks of various "clickable" nanoporous azide-tagged MOFs to flexible organic PG networks by in situ cross-linking with a variety of polyvalent alkynes via copper(I)-catalyzed azide-alkyne cycloaddition (CuAAC), ${ }^{24,25}$ followed by degradation of the metal coordination network (Fig. 4). In previous studies, ${ }^{26}$ the authors had demonstrated the feasibility of the $\mathrm{Cu}(\mathrm{I})$ catalyzed click reactions of azide-tagged MOFs (AzM) with alkynes without disrupting the crystal structures of the MOFs compounds. To demonstrate the conversion of different MOFs into gels, the former were easily prepared by treatment of a diazidetriphenyldicarboxylic acid ligand (AzTPDC) with $\mathrm{Zn}\left(\mathrm{NO}_{3}\right)_{2}$ $\cdot 6 \mathrm{H}_{2} \mathrm{O}$ in DEF at $80{ }^{\circ} \mathrm{C}$ for 3 days. After this time, simple decantation of the solution and washing of the crystal provided cubic AzM with sharp edges. Subsequent reaction of AzM with tetra-acetylene cross-linker (CL4) under the standard click reaction conditions at $80{ }^{\circ} \mathrm{C}$ in the presence of $\mathrm{Cu}^{+}$ as a catalyst in DEF yielded the corresponding cross-linked MOF (CLM) within 1 week. Finally, the coordination of carboxylate anion to $\mathrm{Zn}^{2+}$ ion was eliminated by acidification with concentrated $\mathrm{HCl}$, providing a non-crystalline MOF- templated polymer (MTP) with rougher cubic shapes. Gradual size expansion of the MOFs by acid penetration could be observed under microscopy. In less than $10 \mathrm{~min}$, the cubic crystals of CLM with 300-500 $\mu \mathrm{m}$ in length became cubic polymer gels. Even the cracks or scratches existing on the crystal surfaces were preserved on the gel surface after the hydrolysis reaction. Moreover, AzM treated with diacetylene cross-linker (CL2) instead of CL4 rapidly dissolved, and simultaneous click reaction during the crystallization process of AzM provided only amorphous powdery product. These results demonstrate the importance of both the degree of cross-linking and post-synthetic modification after formation of MOF crystal in order to facilitate the transition from an inorganic nanoporous brittle material to a viscoelastic organic framework.

FT-IR, XPS and ICP-AES measurements demonstrated that 1) all azide groups in the MOF crystals were consumed upon cross-linking, and 2) carboxylate anions were protonated and most $\mathrm{Zn}^{2+}$ ions $(>90 \%)$ removed after acidification. On the other hand, TGA and XRD studies of the crystals before (AzM) and after (CLM) the click reaction indicated no impact of the cross-linking reaction on the thermal stability and inherent network structure.

The so prepared MTP swelled in aprotic polar solvents such as DMF, DEF and DMSO. The swelling without changes in shape and nanoporosity was mainly ascribed to suppression of hydrogen bonds among the carboxylic acid groups. Similarly to common polymer gels bearing carboxylic acids, ${ }^{27}$ the swelling degrees were nearly constant (ca. 1.2) in acidic solutions, but at higher $\mathrm{pH}$ (10.5), the swelling degrees increased ( $c a$. 3.2) due to dissociation of the carboxylic groups, which induced repulsive interaction between anionic groups and generation of osmotic pressure between interior and exterior of MTP. Zinc ion was successfully entrapped in MTP by treatment of zinc nitrate. However, reformation of

(a)

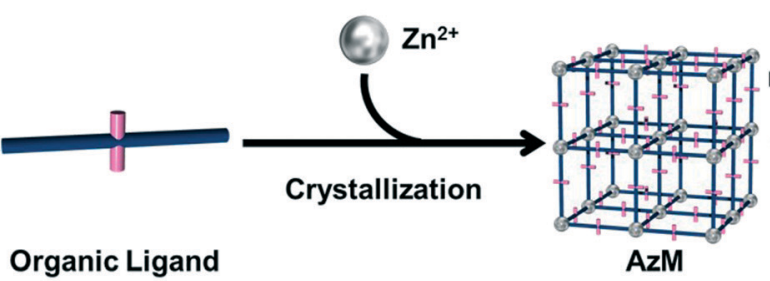

Organic Ligand

AzM

(b)

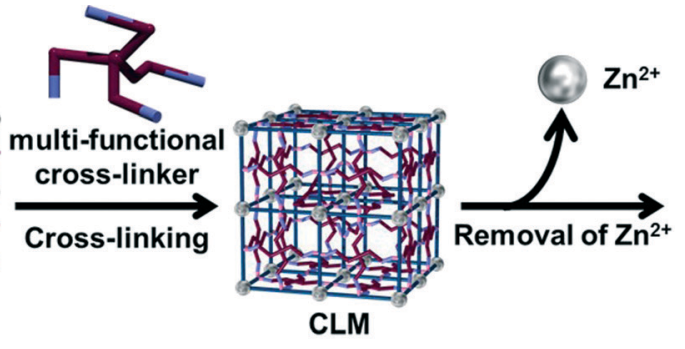

CLM
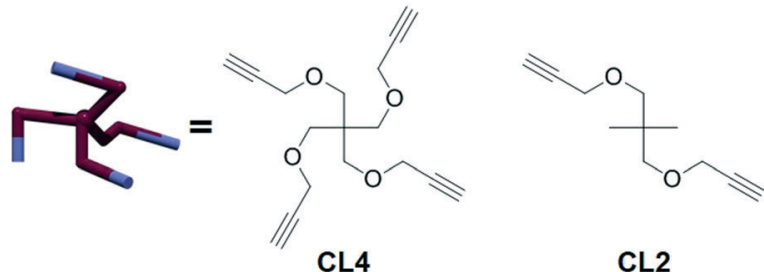

CL2

Fig. 4 (a) Schematic illustration of cross-linking of organic linkers in MOF (AzM) and subsequent degradation to obtain polymer gel (PG). (b) Molecular structures of the organic ligand (AzTPDC) and the cross-linkers (CL4, CL2). Reprinted with permission from ref. 23. Copyright $®$ American Chemical Society. 
zinc carboxylates did not provide back crystallinity to the coordination network due to movement of coordination sites in length ( $c a .10 \%)$ during the swelling process.

Very interestingly, Sada's group could also perform directional and partial hydrolysis of a single piece of CLM crystal to seamlessly fused hybrid material between PG and MOF, the first example of this class. The procedure consisted simply in contacting one crystal face of CLM on a wet membrane with $1 \mathrm{M} \mathrm{NaOH}$ solution for $5 \mathrm{~min}$, followed by immersion in fresh DEF repeatedly to remove excess amount of the base.

The cross-linking of organic ligands in MOF crystals to form PG was successfully generalized by using other MOFs that consisted of biphenyl-type organic linkers with two azide groups (AzBPDC) and some other metal ions (Fig. 5). Treatment of AzBPDC with $\mathrm{Zn}^{2+}$ and $\mathrm{Cu}^{2+}$ provided colorless cubic and green truncated octahedral MOF crystal under standard solvothermal synthesis in DEF and DEF-DMSO, respectively. Moreover, solvothermal synthesis from AzTPDC and $\mathrm{Zr}^{4+}$ in DMF at $120{ }^{\circ} \mathrm{C}$ provided colorless octahedral crystal. XRD and FT-IR analyses of these MOF crystals demonstrated that they had the same crystal structures as their parents without azide groups. Moreover, they were cross-linked by CuAAC and followed by decomposition of metal coordination in acidic medium. After the acid treatment, all the crystals became insoluble and were successfully converted into the corresponding PG materials.

\section{Transformation of metallogels into metal-organic frameworks}

Banerjee and co-workers ${ }^{28}$ has recently closed the loop by developing a strategy to convert metallogels into MOFs. In sharp contrast to the previous examples involving covalent cross-linking, Banerjee's group exploits exchange processes of individual components by intermolecular interactions. As a proof of concept, Fe-based MOFs were in situ synthesized by $\mathrm{PdCl}_{2}$-mediated degradation of Fe-based metallogels. The gradual delivery of both the metal ions and the organic linker necessary for their re-assembly into a crystalline supramolecular structure is a challenging process due to high thermal and chemical stability of such metallogels. ${ }^{29}$

The approach of Banerjee's team involves a very simple one-pot, two-step process. In the first step, MOF precursors $\mathrm{Fe}\left(\mathrm{NO}_{3}\right)_{3} \cdot 9 \mathrm{H}_{2} \mathrm{O}$ and 1,3,5-benzene tricarboxylic acid (BTC) were dissolved in NMF, DMF or DEF (molar ratio Fe: $\mathrm{CO}_{2} \mathrm{H}=$ $1: 3$ ). Orange opaque metallogels were obtained in each solvent after heating the mixture for $6 \mathrm{~h}$ at $90{ }^{\circ} \mathrm{C}$ (Fig. 6). These gels were brittle in nature, as indicated by rheological

(a)

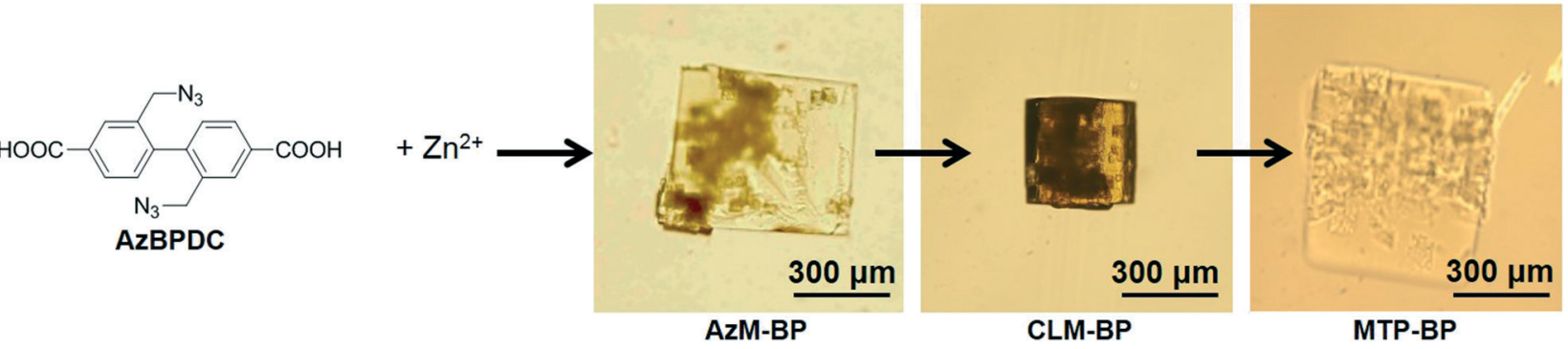

(b)

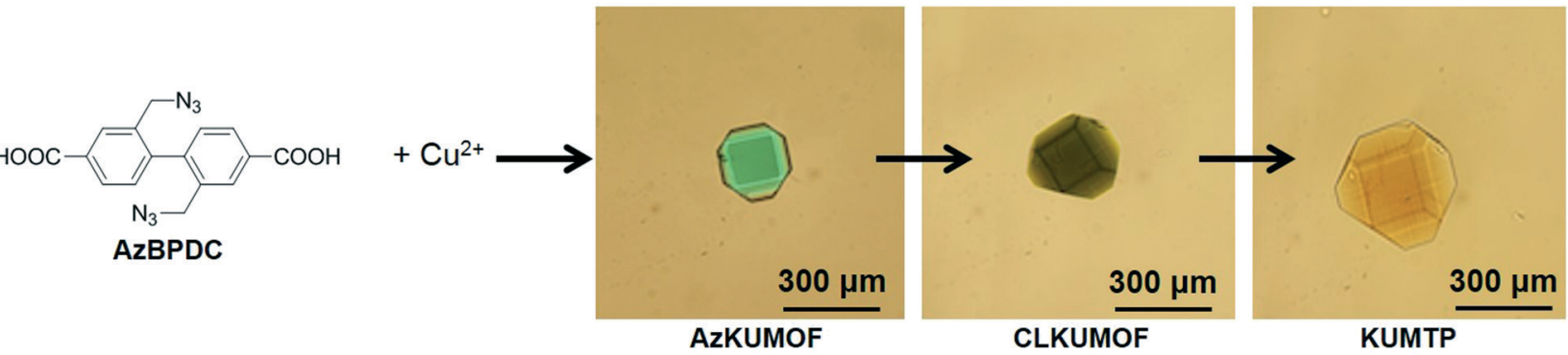

(c)

KUMTP

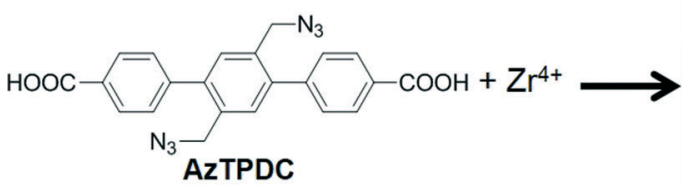

$25 \mu \mathrm{m}$

AzUiOMOF

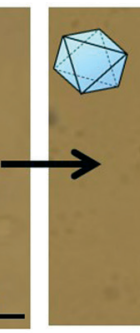

CLUiOMOF

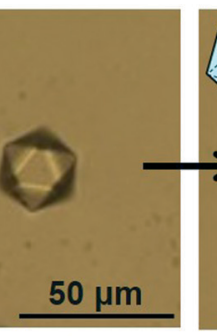

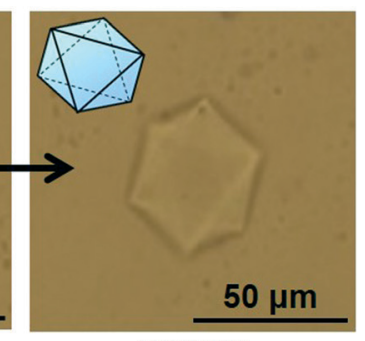

UIOMTP

Fig. 5 Optical microscopy images of (a) AzM-BP, (b) AzKUMOF, and (c) AzUiOMOF, and subsequent cross-linking and transformation into the corresponding MOF-templated polymers (MTPs), respectively. Reprinted with permission from ref. 23. Copyright ${ }^{\circledR}$ American Chemical Society. 


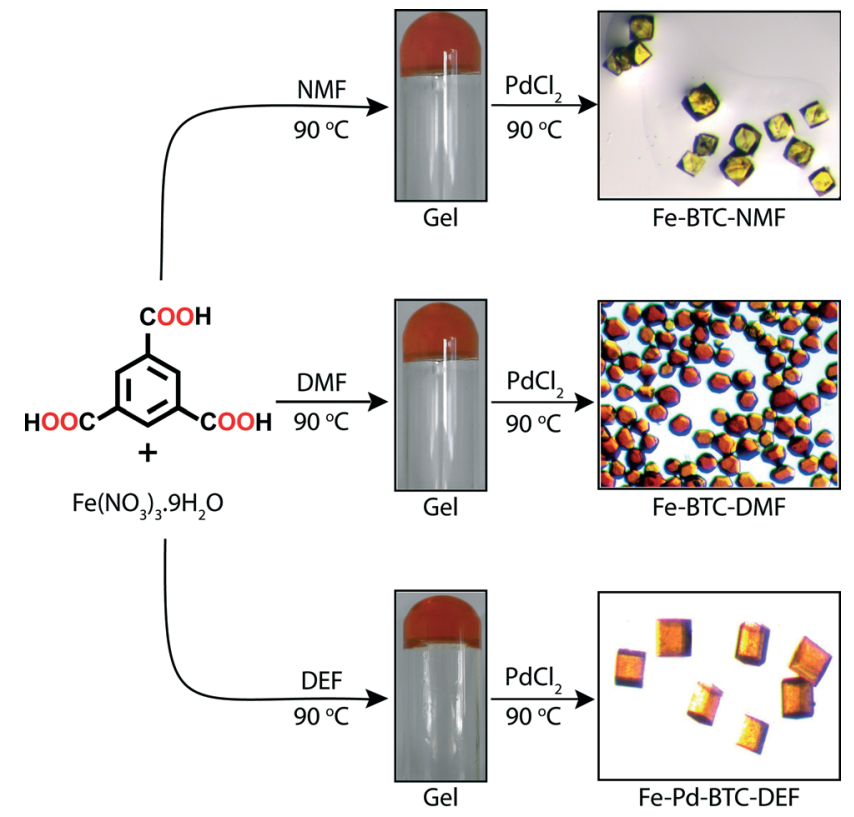

Fig. 6 Formation of Fe-metallogels and their transformation into FeMOFs via $\mathrm{PdCl}_{2}$-mediated gel degradation. Adapted with permission from ref. 28. Copyright ${ }^{\circledR}$ American Chemical Society.

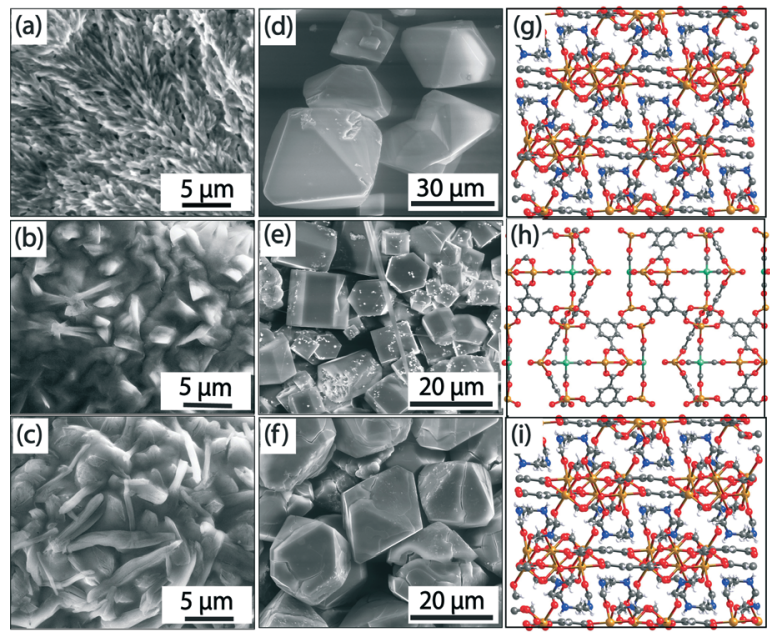

Fig. 7 ESEM images of gels [(a), (b), (c)], SEM images [(d), (e), (f)], and single crystal structures [(g), (h), (i)] of Fe-BTC-NMR, Fe-Pd-BTC-DEF, and Fe-BTC-DMF MOFs, respectively. Color code: $\mathrm{Fe}=$ orange; $\mathrm{O}=$ red; $\mathrm{C}=$ grey; $\mathrm{N}=$ blue; $\mathrm{Pd}=$ green. Palladium residues on crystal faces are visible in Fe-Pd-BTC-DEF (e). Adapted with permission from ref. 28. Copyright ${ }^{\circledR}$ American Chemical Society.

measurements, and remained stable over weeks. ESEM revealed typical fibrillar morphologies of the supramolecular aggregates (Fig. $7(\mathrm{a}-\mathrm{c})$ ). In the second step, a solution of $\mathrm{PdCl}_{2}$ (molar ratio $\mathrm{Fe}: \mathrm{Pd}=1: 1$ ) was added to the Fe-based metallogels and kept for $48 \mathrm{~h}$ at $90{ }^{\circ} \mathrm{C}$ to induce the degradation of the gel phase (after $24 \mathrm{~h}$ ) and consequent thermodynamically controlled transformation into Fe-MOFs with welldefined faces as observed by SEM (Fig. 7 (d-f)). Traditionally, the solvents chosen in this approach are considered ideal for MOF synthesis due to their high boiling points and partial hydrolytic decomposition into corresponding amines and formic acid at higher temperature. The in situ formation of these amines has proven to deprotonate the ligand making the use of additional bases unnecessary. ${ }^{30}$ On the other hand, hydrogen-bond donors such as formic acid could also be involved in the stabilization of supramolecular gel phases. ${ }^{31}$

This facile protocol allowed the fabrication of a known MOF (i.e., Fe-BTC-DMF) ${ }^{17}$ and two new MOFs (i.e., Fe-BTCNMF (2D) and Fe-Pd-BTC-DEF (3D)) (Fig. 7 (g-i)) in pure crystalline forms as indicated by PXRD analyses. Fe-BTC-NMF crystallized in trigonal space group $R \overline{3}$. In the extended crystal structure, $\mathrm{Fe}^{3+}$ adopts an octahedral geometry coordinated to five oxygens from $\mu_{2}-\mathrm{CO}_{2}{ }^{-}$functionalities of BTC and one NMF oxygen atom. On the other hand, short-lived Fe-Pd-BTCDEF crystallized in hexagonal space group $P 6_{3} / m m c$ and the secondary building unit contains two metal centers, Fe(II) and $\mathrm{Pd}(\mathrm{II})$. In the extended structure, one set of Fe centers is tetrahedrally coordinated to four $\mathrm{O}$ atoms, and another $\mathrm{Fe}$ is coordinated to five $\mathrm{O}$ atoms forming a square pyramidal geometry. The $\mathrm{Pd}(\mathrm{II})$ adopts a square planar geometry and is coordinated with four $\mathrm{C}$ atoms of $\mathrm{CO}$ molecules, which could be generated along the pathway of formic/formamide oxidation as suggested by continuous monitoring the gel-to-MOF transition by GC and a series of control experiments. In addition, formation of palladium black (confirmed from PXRD) was also observed indicating a close association between the reduction of $\mathrm{PdCl}_{2}$ and the onset of metallogel degradation. Therefore, a judicious balance between formulation components and hydrothermal stability of solvent molecules is required to drives the gel phase into MOFs. This work is especially relevant if we consider that standard bulk synthesis of Fe-based MOFs suffer from major limitations due to the easy oxidation of $\mathrm{Fe}^{2+}$ and ready hydrolysis of $\mathrm{Fe}^{3+}$ under hydrothermal conditions. ${ }^{32}$

Despite the attractiveness of the previous example, no quantitative conversion of the gels into the corresponding MOFs was achieved (approximately 80\% yield was obtained with each gel). However, the same research group ${ }^{33}$ reported a few months later a one-pot synthesis of a metallohydrogel (ZAVA gel) $^{34}$ and the in situ entrapment of uncapped CdS quantum dots to yield a luminescent metallohydrogel (CdS@ZAVA gel) (Fig. 8).

Briefly, ZAVA gel can be easily prepared after mixing stock solutions of zinc acetate dihydrate $(\mathrm{ZA})$ and the acetate salt of L-3-methyl-2-(pyridin-4-ylmethylamino)butanoic acid (VA). Immobilization of quantum dots takes place efficiently upon addition of aqueous solutions of $\mathrm{CdCl}_{2} \cdot \mathrm{H}_{2} \mathrm{O}$ and $\mathrm{Na}_{2} \mathrm{~S}$ to the colloidal intermediate phase prior gelation. Very interestingly, CdS@ZAVA gel can be degraded and converted quantitatively into luminescent CdS-embedded MOF (CdS@ZAVCl MOF) via a simple and unique NaCl-mediated gradual degradation of the gel phase at room temperature (Fig. 9). The crystal structure of pure ZAVCl MOF (without CdS quantum dots) obtained by the same method revealed the presence of 


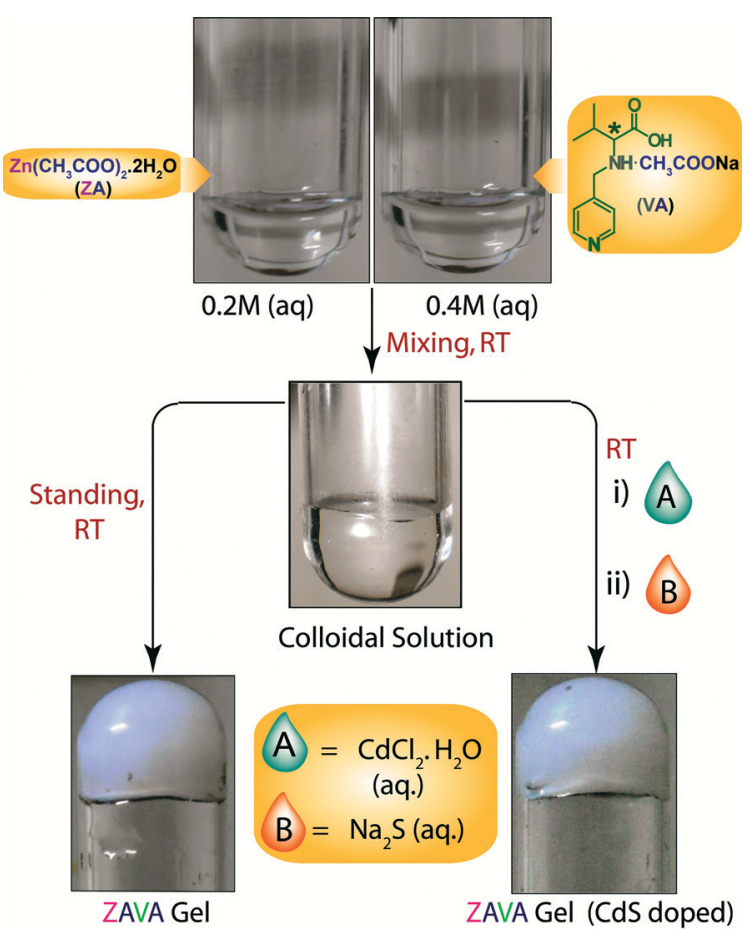

Fig. 8 Room temperature synthesis of ZAVA gel and CdS-loaded ZAVA gel. Adapted with permission from ref. 33. Copyright ${ }^{\circledR}$ American Chemical Society. a chloride ion in the coordination sphere of $\mathrm{Zn}^{2+}$ along with two oxygens (from two carboxylate groups) and two nitrogens (one from pyridine and one from the amine of the ligand). ${ }^{35}$ On the other hand, PXRD analyses showed that immobilization of CdS particles did not cause alteration of the crystalline phase in comparison to pristine ZAVCl MOF. The ability of ZAVA gel to immobilize CdS particles was attributed to the presence of a pyridine moiety in the ligand (VA). In addition, the pyridinic nitrogen of VA is also involved in the formation of the hydrogen-bonded gel network, ${ }^{34}$ thus offering a remarkable dual stabilization role.

It is worth mentioning that the conventional sovothermal method employs high-temperature conditions $\left(90^{\circ} \mathrm{C}\right)$ yielding small MOFs $(c a .50 \mu \mathrm{m}) .^{35}$ However, the room temperature gel-to-MOF approach affords millimeter sized rodshaped, transparent ZAVCl MOF crystals (Fig. 9). Considering the constant photoluminescence of these MOFs after several washings in water, as well as their pore dimension $(1.2 \mathrm{~nm})$, CdS quantum dots ( $c a .5-9 \mathrm{~nm}$ in diameter, as determined by HRTEM) are presumably sandwiched between crystallite surfaces of ZAVCl MOF. ${ }^{36}$

Last but not least, the so obtained CdS@ZAVCl MOF could also be used as an efficient photocatalyst for water-splitting under both $\mathrm{UV}$ and visible light irradiation (i.e., $\mathrm{H}_{2}$ evolution $500-510 \mu \mathrm{mol} \mathrm{h}^{-1} \mathrm{~g}^{-1}$ ) in spite of the low loading of the

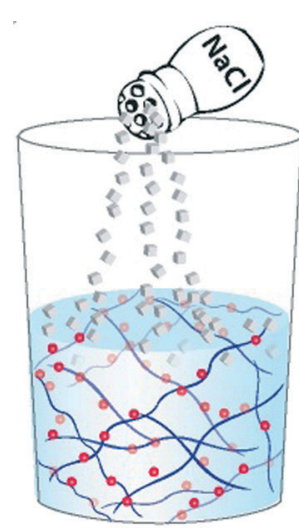

CdS@ZAVAgel

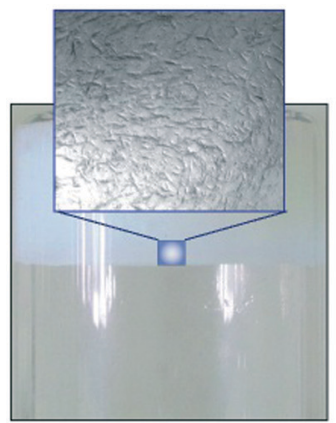

CdS@ZAVA gel

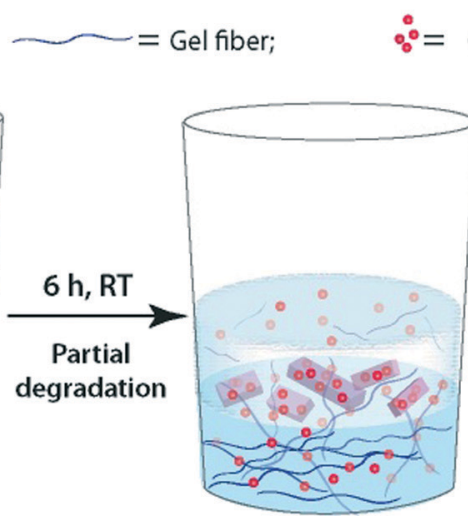

DegradedCdS@ZAVA gel + ZAVCI MOF

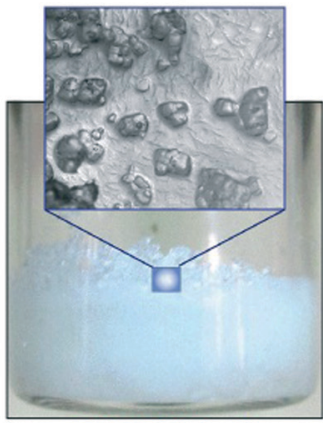

CdS@ZAVA gel $+\mathrm{NaCl}(\mathrm{Oh})$

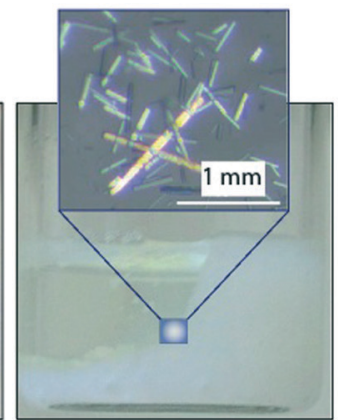

CdS@ZAVCI MOF (6h)
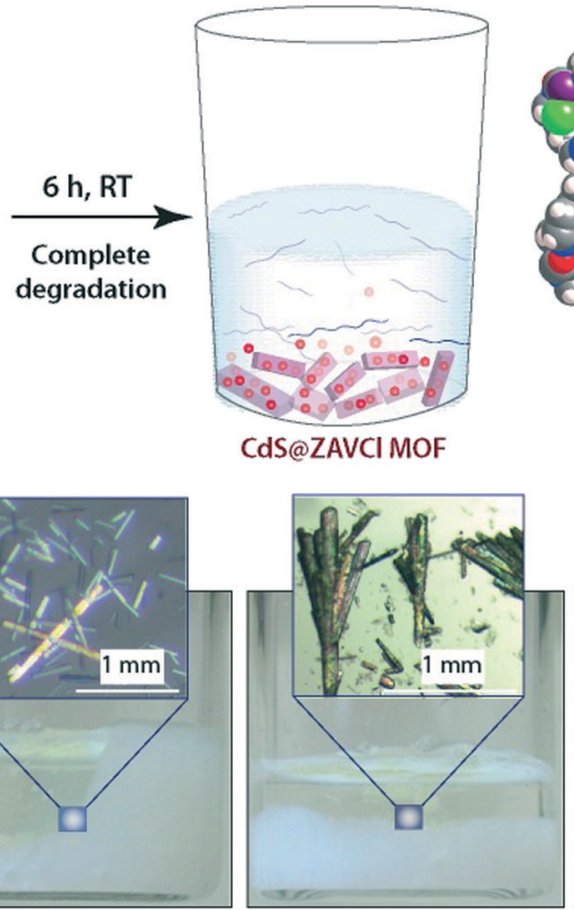

CdS@ZAVCI MOF (8h)

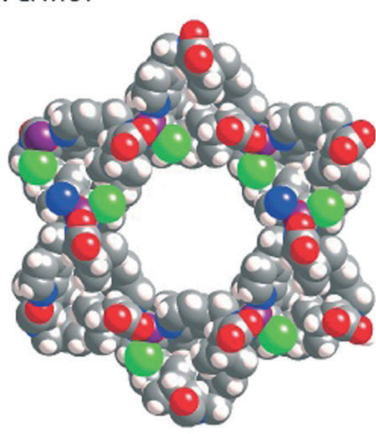

ZAVCI MOF

(Crystal Structure)

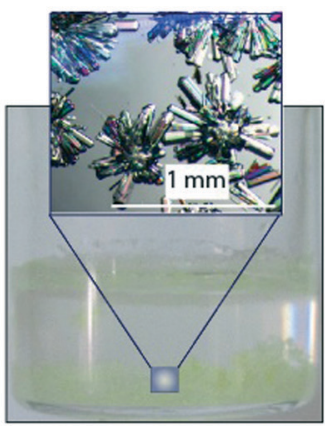

CdS@ZAVCI MOF (12h)

Fig. 9 Top: Synthesis of CdS loaded ZAVCI MOF (CdS@ZAVCI MOF) from CdS loaded ZAVA gel (CdS@ZAVA gel), and space-filling representation of the crystal structure of ZAVCl (view through $c$ axis. Color code: $\mathrm{C}=$ grey; $\mathrm{H}=$ white; $\mathrm{Zn}=$ purple; $\mathrm{Cl}=\mathrm{green} ; \mathrm{N}=$ blue; $\mathrm{O}=$ red). Bottom: Realtime digital photographs of CdS@ZAVA gel to CdS@ZAVCI MOF conversion process. Adapted with permission from ref. 33. Copyright $₫$ American Chemical Society. 
semiconductor in the material (ca. $1 \mathrm{wt} \%)$. Although there exist few reports on the utilization of CdS-MOF composites for water-splitting, ${ }^{37}$ their preparation require very high temperatures and much longer reaction times in comparison to CdS@ZAVCl MOF.

\section{Summary and outlook}

Until now, most research on MOFs and gel materials has remained as important topics albeit in very different fields. This has been mainly motivated by the opposite mechanical properties of both types of materials (i.e., hard vs. soft). However, Sada's group has demonstrated the possibility to transform rigid cubic MOF crystals into flexible polymer gel particles via internal cross-linking of the organic linkers in the void spaces, followed by loss of coordination metal ions. Remarkably, the resulting micro- or nanosized gel networks retained the shape and size of the original MOF crystals employed as templates in this approach. In addition, the first chimera-type hybrid material consisting of MOF and polymer gel was also obtained by directional and partial hydrolysis of resulting cross-linked MOF. On the other hand, Banerjee's group has recently advanced in the field by developing a simple and very efficient route for the synthesis of Fe-MOF crystals via $\mathrm{PdCl}_{2}$-mediated Fe-metallogel degradation. The bulk synthesis of such Fe-MOFs by standard hydrothermal methods is difficult due to the easy oxidation of $\mathrm{Fe}^{2+}$ and ready hydrolysis of $\mathrm{Fe}^{3+}$. Moreover, the same group also succeeded in preparing CdS quantum dot-loaded gel, which was then transformed quantitatively into luminescent MOF crystals by simple addition of chloride salt. The entire method works at room temperature and the so prepared MOFs were efficiently used as photocatalysts in visible light water-splitting reactions.

Although fully reversible conversion between MOF and gels is still in demand to switch back and forth between different degrees of firmness, the works highlighted here represent a novel archetype in the growing areas of crystal engineering and stimuli-responsive gels. New bridges between crystalline (hard) and amorphous (soft) functional materials are now accessible, making possible to prepare one from the other in a simple way and with memory of specific features of the initial state. These results, together with envisioned future studies on the underlying physics and thermodynamics of these phase transitions, also open a new horizon toward the preparation of novel model networks and dynamic metal-biomolecule frameworks ${ }^{38}$ with precise properties.

\section{Acknowledgements}

Financial from DFG (PRJ 9209720) and Universität Regensburg are gratefully acknowledged. D.D.D. thanks Deutsche Forschungsgemeinschaft (DFG) for the Heisenberg Professorship Award.

\section{Notes and references}

1 S. Banerjee, R. K. Das and U. Maitra, J. Mater. Chem., 2009, 19, 6649; R. G. Weiss and P. Terech, Molecular Gels: Materials with Self-Assembled Fibrillar Networks, Springer, New York, 2006.

2 E. Zaccarelli, J. Phys.: Condens. Matter, 2007, 19, 323101; O. Gronwald, E. Snip and S. Shinkai, Curr. Opin. Colloid Interface Sci., 2002, 7, 148.

3 M. O. M. Piepenbrock, G. O. Lloyd, N. Clarke and J. W. Steed, Chem. Rev., 2010, 110, 1960; R. V. Ulijn and A. M. Smith, Chem. Soc. Rev., 2008, 37, 664.

4 Y. Osada and A. R. Khokhlov, Polymer Gels and Networks, Marcel Dekker, New York, 2002.

5 X. Yang, G. Zhang and D. Zhang, J. Mater. Chem., 2012, 22, 38; D. J. Adams, Macromol. Biosci., 2011, 11, 160.

6 A. Ajayaghosh, V. K. Praveen and C. Vijayakumar, Chem. Soc. Rev., 2008, 37, 109.

7 A. H. Chughtai, N. Ahmad, H. A. Younus, A. Laypkov and F. Verpoort, Chem. Soc. Rev., 2015, DOI: 10.1039/C4CS00395K; H. Furukawa, K. E. Cordova, M. O'Keeffe and O. M. Yaghi, Science, 2013, 341, 1230444; G. K. H. Shimizu, J. M. Taylor and S. Kim, Science, 2013, 341, 354; S. Sen, N. N. Nair, T. Yamada, H. Kitagawa and P. K. Bharadwaj, J. Am. Chem. Soc., 2012, 134, 19432; L. J. Murray, M. Dinca and J. R. Long, Chem. Soc. Rev., 2009, 38, 1294; A. U. Czaja, N. Trukhan and U. Mueller, Chem. Soc. Rev., 2009, 38, 1284; J. Lee, O. K. Farha, J. Roberts, K. A. Scheidt, S. T. Nguyen and J. T. Hupp, Chem. Soc. Rev., 2009, 38, 1450.

8 H. Al-Kutubi, J. Gascon, E. J. R. Sudhoelter and L. Rassaei, ChemElectroChem, 2015, 2, 462; N. A. Khan and S. H. Jhung, Coord. Chem. Rev., 2015, 285, 11; O. Karagiaridi, W. Bury, J. E. Mondloch, J. T. Hupp and O. K. Farha, Angew. Chem., Int. Ed., 2014, 53, 4530; J. L. C. Rowsell and O. M. Yaghi, Microporous Mesoporous Mater., 2004, 73, 3.

9 E. A. Flügel, A. Ranft, F. Haase and B. V. Lotsch, J. Mater. Chem., 2012, 22, 10119.

10 E.-M. Schön, S. Roelens and D. D. Díaz, CrystEngComm, 2015, DOI: 10.1039/C5CE00397K; Y. Lan, M. G. Corradini, R. G. Weiss, S. R. Raghavan and M. A. Rogers, Chem. Soc. Rev., 2015, DOI: 10.1039/C5CS00136F; Y. Yin, Z. Gao, Y. Bao, B. Hou, H. Hao, D. Liu and Y. Wang, Ind. Eng. Chem. Res., 2014, 53, 1286; I. Kapoor, E.-M. Schön, J. Bachl, D. Kühbeck, C. Cativiela, S. Saha, R. Banerjee, S. Roelens, J. J. MarreroTellado and D. D. Díaz, Soft Matter, 2012, 8, 3446; D. J. Adams, K. Morris, L. Chen, L. C. Serpell, J. Bacsa and G. M. Day, Soft Matter, 2010, 6, 4144; Y. Wang, L. Tang and J. Yu, Cryst. Growth Des., 2008, 8, 884.

11 D. Krishna Kumar and J. W. Steed, Chem. Soc. Rev., 2014, 43, 2080.

12 Y. Xu, C. Khang, Y. Chen, Z. Bian, X. Qiu, L. Gao and Q. Meng, Chem. - Eur. J., 2012, 18, 16955; P. Zhu, X. Yan, Y. Su, Y. Yang and J. Li, Chem. - Eur. J., 2010, 16, 3176.

13 C. D. Jones, J. C. Tan and G. O. Lloyd, Chem. Commun., 2012, 48, 2110.

14 G. Nandi, H. M. Titi, R. Thakuria and I. Goldberg, Cryst. Growth Des., 2014, 14, 2714; A. Mallick, E.-M. Schön, T. 
Panda, K. Sreenivas, D. D. Díaz and R. Banerjee, J. Mater. Chem., 2012, 22, 14951.

15 N. Ahmad, M. M. Ahmad and P. N. Kotru, J. Cryst. Growth, 2015, 412, 72; L. Meazza, J. A. Foster, K. Fucke, P. Metrangolo, G. Resnati and J. W. Steed, Nat. Chem., 2013, 5, 42; R. Daly, O. Kotova, M. Boese, T. Gunnlaugsson and J. L. Boland, ACS Nano, 2013, 7, 4838; V. R. Thalladi, S. Brasselet, H.-C. Weiss, D. Bläser, A. K. Katz, H. L. Carrell, R. Boese, J. Zyss, A. Nangia and G. R. Desiraju, J. Am. Chem. Soc., 1998, 120, 2563; G. R. Desiraju, D. Y. Curtin and I. C. Paul, J. Am. Chem. Soc., 1977, 99, 6148.

16 O. M. Yaghi, G. Li and H. Li, Chem. Mater., 1997, 9, 1074.

17 J. A. Foster, M. O. M. Piepenbrock, G. O. Lloyd, N. Clarke, J. A. K. Howard and J. W. Steed, Nat. Chem., 2010, 2, 1037.

18 C. Sudha, P. Parimaladevi and K. Srinivasan, Mater. Sci. Eng., C, 2015, 47, 150; F. Aparicio, E. Matesanz and L. Sánchez, Chem. Commun., 2012, 5757; D. Braga, S. d'Agostino, E. D'Amen, F. Grepioni, D. Genovese, L. Prodi and M. Sgarzi, Dalton Trans., 2013, 42, 16949; D. Braga, S. d'Agostino, E. D'Amen and F. Grepioni, Chem. Commun., 2011, 5154.

19 T. K. Adalder and P. Dastidar, Cryst. Growth Des., 2014, 14, 2254; T. K. Adalder, U. K. Das, J. Majumder, R. Roy and P. Dastidar, J. Indian Inst. Sci., 2014, 94, 9; T. K. Adalder, D. P. Kumar and P. Dastidar, Cryst. Growth Des., 2014, 14, 11; S. Banerjee, N. N. Adarsh and P. Dastidar, Soft Matter, 2012, 8, 7623; N. N. Adarsh and P. Dastidar, Cryst. Growth Des., 2011, 11, 328; N. N. Adarsh, P. Sahoo and P. Dastidar, Cryst. Growth Des., 2010, 10, 4976.

20 N. M. Dixit and C. F. Zukoski, Phys. Rev. E: Stat., Nonlinear, Soft Matter Phys, 2003, 67, 061501.

21 Y. Furukawa, T. Ishiwata, K. Sugikawa, K. Kokado and K. Sada, Angew. Chem., Int. Ed., 2012, 51, 10566.

22 Y. Xia, Y. Xiong, B. Lim and S. E. Skrabalak, Angew. Chem., Int. Ed., 2009, 48, 60.

23 T. Ishiwata, Y. Furukawa, K. Sugikawa, K. Kokado and K. Sada, J. Am. Chem. Soc., 2013, 135, 5427.

24 V. V. Rostovtsev, L. G. Green, V. V. Fokin and K. B. Sharpless, Angew. Chem., Int. Ed., 2002, 41, 2596.

25 C. W. Torøe, C. Christensen and M. Meldal, J. Org. Chem., 2002, 67, 3057.

26 Y. Goto, H. Sato, S. Shinkai and K. Sada, J. Am. Chem. Soc., 2008, 130, 14354.

27 J. Ricka and T. Tanaka, Macromolecules, 1984, 17, 2916.
28 H. B. Aiyappa, S. Saha, B. Garai, J. Thote, S. Kurungot and R. Banerjee, Cryst. Growth Des., 2014, 14, 3434.

29 S. K. Nune, P. K. Thallapally and B. P. McGrail, J. Mater. Chem., 2010, 20, 7623; M. R. Lohe, M. Rose and S. Kaskel, Chem. Commun., 2009, 6056.

30 L. Rajput, D. Kim and M. S. Lah, CrystEngComm, 2013, 15, 259; A. D. Burrows, K. Cassar, R. M. W. Friend, M. F. Mahon, S. P. Rigbyb and J. E. Warren, CrystEngComm, 2005, 7, 548.

31 D. K. Smith, Self-assembling fibrillar networksSupramolecular gels, in, Supramolecular Chemistry: From Molecules to Nanomaterials, ed. J. W. Steed and A. P. Gale, Wiley \& Sons Ltd., Chichester, UK, 1st edn, 2012, vol. 7, pp. 3355-3376; D. D. Díaz, D. Kühbeck and R. J. Koopmans, Chem. Soc. Rev., 2011, 40, 427; T. Yu, R. Cristiano and R. G. Weiss, Chem. Soc. Rev., 2010, 39, 1435; Y. Gao, F. Zhao, Q. G. Wang, Y. Zhang and B. Xu, Chem. Soc. Rev., 2010, 39, 3425.

32 K. Kongpatpanich, S. Horike, M. Sugimoto, S. Kitao, M. Setoc and S. Kitagawa, Chem. Commun., 2014, 50, 2292; L. Xie, S. Liu, C. Gao, R. Cao, J. Cao, C. Sun and Z. Su, Inorg. Chem., 2007, 46, 7782; P. Horcajada, S. Surble, C. Serre, D. Y. Hong, Y. K. Seo, J. S. Chang, J. M. Greneche, I. Margiolaki and G. Ferey, Chem. Commun., 2007, 2820; T. R. Whitfield, X. Wang, L. Liu and A. Jacobson, ECS J. Solid State Sci. Technol., 2005, 7, 1096; C. Serre, F. Millange, S. Surble and G. Ferey, Angew. Chem., Int. Ed., 2004, 43, 6286; C. Serre, F. Millange, S. Surble, J.-M. Greneche and G. Ferey, Chem. Mater., 2004, 16, 2706.

33 S. Saha, G. Das, J. Thote and R. Banerjee, J. Am. Chem. Soc., 2014, 136, 14845.

34 S. Saha, J. Bachl, T. Kundu, D. D. Díaz and R. Banerjee, Chem. Commun., 2014, 3004; S. Saha, J. Bachl, T. Kundu, D. D. Díaz and R. Banerjee, Chem. Commun., 2014, 7032.

35 S. C. Sahoo, T. Kundu and R. Banerjee, J. Am. Chem. Soc., 2011, 133, 17950.

36 D. Buso, J. Jasieniak, M. D. H. Lay, P. Schiavuta, P. Scopece, J. Laird, H. Amenitsch, A. J. Hill and P. Falcaro, Small, 2012, 8, 80.

37 R. Lin, L. Shen, Z. Ren, W. Wu, Y. Tan, H. Fu, J. Zhang and L. Wu, Chem. Commun., 2014, 50, 8533; J. He, Z. Yan, J. Wang, J. Xie, L. Jiang, Y. Shi, F. Yuan, F. Yu and Y. Sun, Chem. Commun., 2013, 49, 6761.

38 I. Imaz, M. Rubio-Martínez, J. An, I. Solé-Font, N. L. Rosi and D. Maspoch, Chem. Commun., 2011, 7287. 